\title{
Understanding Continuous Use Intention of MOOCs -A Perspective from Subjective Task Value
}

\author{
Genfu Yang* \\ School of digital media and design \\ HangZhou Dianzi University, \\ HangZhou, China \\ ygfsn@hdu.edu.cn
}

\begin{abstract}
Although MOOCs have developed rapidly in recent years, little is known about learner engagement. This paper integrates ECM and subjective task value to analyze the influencing factors of MOOCs users' intention to continue to use. A total of 294 learners participated in the survey. The research shows that the three factors of achievement value, intrinsic value and utility value in subjective task value theory have a significant positive impact on the learner's intention to use, and learners pay more attention to the practicality of the course. Second, user anxiety and risk of arbitrary learning have a significant negative impact on their continued intention to use, and social isolation and response delays have little effect on them. This study will help to explore the characteristics and success factors of MOOCs systems to help organizations reduce the risk of failure and overcome obstacles in the implementation of MOOCs.
\end{abstract}

Keywords-MOOCs; continuance intention; subjective task value; achievement value; social isolation; anxiety

\section{INTRODUCTION}

In recent years, with the emergence of Massive Open Online Courses (MOOCs), the paradigm of online learning has changed. As a new online education model, MOOCs provides an opportunity to realize the transformation and innovation of education mode with its characteristics of openness, autonomy and networking. It also makes learning for lifelong learning possible (Waldrop, 2013)[1]. However, the MOOCs learning approach also brings a lot of uncertainty. Studies have shown that MOOCs learning have problems such as low completion rate, weak participation, and poor interactivity. It is common for users to give up after initial use (Adams \& Williams, 2013; Bartolome \& Steffens, 2015) [2-3]. Previous studies have analyzed various reasons for MOOCs learners' dropout. For example, learners participate in MOOCs motivations and learning objectives (Barba, Kennedy, \& Ainley, 2016) [4], learners' online learning skills (Fan Wenqiang, 2012), openness of the curriculum and the reputation of teachers or schools (Khaled M. Alraimi et al., 2015) [5], the difficulty and interactivity of the course (Liqiang Huang, et al., 2017) [6]. However, little are known about the value factors that encourage learners to continue to participate in MOOCs. Previous researchs have shown that, regardless of the use of any kind of information system, the trade-off between perceived and perceived costs, that is, the value factor has an

HangZhou Dianzi University Humanities and Social Science Fund (2017B08) important impact on sustained intention.

The purpose of this paper is to explore the relationship between value factors and ongoing participation, and to analyze factors that increase the continued intention of learners. We integrate the information system continuous use model (Expectation Confirmation Model - ECM) with the learner's subjective task value into a unified framework to explore the impact of these characteristics on the MOOC's intention to participate. ECM explains why a person continues or abandons the use of information systems through perceived usefulness, expectations, and satisfaction (Bhattacherjee, 2001). Eccles et al. (1987) the Achievement Motivation Expectation Value Model relates individual choice, persistence, and performance to expectations of success and subjective task value. The model outlines the motivational components of subjective task value: achievement value, intrinsic value and utility value, and cost. Studies have shown that subjective task value is an important factor in predicting the continued use of intention and performance in course learning, such as mathematics, physics and English. Therefore, in this paper, the motivational factors of subjective task value are integrated into the ECM, and the factors affecting the intention to use MOOCs are analyzed. This study will help to explore the characteristics and success factors of MOOCs systems and their impact on the continued intention of learners to help organizations reduce the risk of failure and overcome obstacles in the implementation of MOOCs.

\section{RESEARCH Model AND HyPOTHESES}

MOOC is an emerging application of the Internet, unlike the information systems used in the workplace. The variables of the Expectation Confirmation Model (ECM) do not fully reflect the learner's motivation. Homer and Kahle believe that values are a social factor that guides individual behavior and provide a basis for understanding cultural and intercultural human behavior. Therefore, we extend the Expectation Confirmation Model (ECM) by adding subjective task values. The subjective task value consists of two parts: perceived benefit and perceived cost. The perceived income part includes achievement value, intrinsic value and utility value. The utility value is similar to the concept of perceived usefulness in the ECM. The cost of the subjective task value is conceptualized as a negative aspect of the focused task. In this study, we identified four negative aspects of MOOCs learning: social 
isolation, anxiety, delayed response, and risk of casual learning. Figure 1 shows the research model, in addition to the intention to use in the ECM, the value of achievement, intrinsic value and practical value are added to the model.

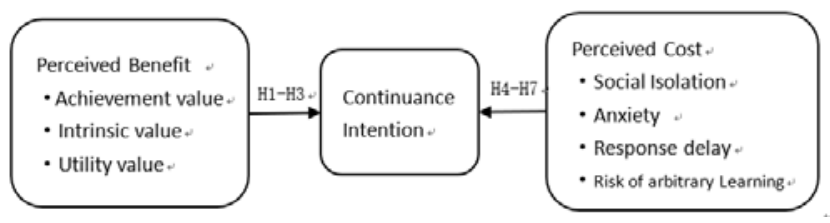

Fig. 1. Research model.

\section{A. Achievement value}

Achievement value refers to the importance of establishing a good self-image and establishing core personal values (such as personal achievement and ability needs). In general, if learners value a task, they will be more likely to do the task, work harder, and perform well. Some research on traditional classroom education also supports this view. For example, Meece et al. (1983) found that the achievement value of junior high school students heralded their intention to continue learning mathematics. Therefore, we propose the following research hypotheses:

H1: Learners' achievement value positively influences their continuance intention of MOOCs.

\section{B. Intrinsic value}

Intrinsic value is the extent to which an activity is considered to be personal enjoyment. According to the theory of self-determination, if learners are interested in MOOCs or enjoy the process, they are internally driven and free to decide whether to continue the course. Bong (2001) found that if students have an intrinsic interest in topics in the classroom, these students are more likely to choose similar courses in the future. Therefore, we propose the following research hypotheses:

H2: Learners' intrinsic value positively influences their continuance intention of MOOCs.

\section{Utility value}

Utility value measures how a system relates to current and future career goals, such as promotion and salary. Practical value is similar to long-term utility or outcome, and is an extrinsic motivation that is similar to perceived usefulness. In the ECM, perceived usefulness is a key motivating factor affecting satisfaction and intention to continue to use (Bhattacherjee, 2001). Therefore, the utility value (perceived usefulness belief) in the use of MOOCs will affect the learner's satisfaction and subsequent intention to continue to use. So, we propose the following research hypotheses:

H3: Learners' utility value positively influences their continuance intention of MOOCs.

\section{Social isolation}

While MOOCs provide convenience and flexibility for learning, learners also feel the lack of interaction and emotional care. Social isolation occurs when there is less opportunity for learners to interact with other learners or teachers. If it is geographically separated from time and space, the interaction is usually asynchronous and is a form of textual information. This can lead to socialization being suppressed or isolated. Bennett et al. (1999) show that online learning students are often influenced by social isolation and ultimately lead to student withdrawal. So, we propose the following research hypotheses:

$\mathrm{H} 4$ : Social isolation has a negative impact on the continued intention to use MOOCs.

\section{E. Anxiety}

Anxiety refers to the fear or discomfort experienced by an individual using technology. Ontologists believe that anxiety is "a psychological experience that inevitably exists when individuals face free choice." During the use of MOOCs, learners may have an anxiety when making their own decisions and learning pace. This anxiety creates an emotional response, a fear of potential negative effects, such as a low expected learning performance or a lack of control over the learning process. It is believed that negative emotions such as these deviate from task performance, and through perceived behavior control, have a significant impact on the learner's continued intention. So, we propose the following research hypotheses:

H5: Anxiety has a significant negative impact on the continued willingness to use MOOCs.

\section{F. Response delay}

The response delay is a lack of immediacy in receiving responses from the system. In the MOOCs service, the response delay means that the learner cannot get the timely response of the teacher or other learners during the learning process, thus affecting the enthusiasm of the learning. Vonderwell (2003) showed that one of the disadvantages of online learning is that they lack immediate feedback from teachers. Hara and Kling (1999) showed in the study of students' distance learning that participants were frustrated by the lack of immediate response. So, we propose the following research hypotheses:

H6: Response delay has a negative impact on MOOC's intention to continue to use.

\section{G. Risk of arbitrary learning}

There is a risk of arbitrary learning when learners have difficulty self-motivation. A key feature of MOOCs is that learners control the speed of learning themselves. This way of learning a student's self-determination process may cause a great psychological burden on students, making it difficult for them to maintain interest, focus, and be stable for a long time. In a survey of learners' perceptions of online learning, Song et al. (2004) revealed that most learners believe that learning motivation and time management can influence the success of their online learning experience. Therefore, we believe that learners with lower motivation or bad study habits tend to fall behind and lead to lower learning performance. So, make the following assumptions:

H7: The risk of arbitrary learning has a negative impact on the continued intention to use MOOCs. 


\section{Data Collection}

This study used a questionnaire survey to collect data using the seven-level Likert score, with "1-strong opposition" and "7strong agreement”. The questionnaire was adapted based on previous studies, and the measurement questions of continuance intention to use were adapted from the literature (Bhattacherjee, 2001). The measurement questions of achievement value, intrinsic value and utility value have been studied by scholars such as Battle and Wigfield (2003) and Chao-Min Chiu (2008)[6], social isolation, anxiety, response delay, and risk of arbitrary learning. The construct refers to the study by Chao-Min Chiu (2008). The questions of the eight constructs were finally discussed by experts and a small range of pre-tests to determine 25 questions. The questionnaire was distributed on the professional questionnaire website "Questionnaire Star", and 400 participants were invited to participate in the form of paid sample services. After removing the invalid samples, 294 valid samples were finally retained, and the recovery efficiency was $73.5 \%$.

Among the participants, female users accounted for $53.4 \%$, slightly more than male users; the respondents were mainly concentrated in $25-45$ years old, accounting for $83.34 \%$ of the total sample; in terms of academic qualifications, undergraduates accounted for $80.27 \%$. The number of users with master's degree or above accounted for $9.52 \%$, and the number of students with junior college degree or below accounted for $10.20 \%$. In terms of occupation, the sample mainly consisted of $79.59 \%$ of employees, accounting for $7.92 \%$, and $7.82 \%$ of college students; In terms of MOOCs experience, users with more than half a year of experience accounted for $85.71 \%$.

\section{DATA ANALYSIS}

In this study, the partial least squares PLS (Partial Least Squares PLS) was used to analyze the data and calculate the reliability and validity of the model structure. PLS is a technique that can be used for measurement model and structural model analysis. It combines confirmatory factor analysis and linear regression to solve regression modeling with fewer sample points than variables. It can solve more complex variables. The relationship is explained to avoid the problem of insufficient explanatory power. This study used SmartPLS for verification of measurement models and structural models.

\section{A. Measurement model}

Fornell and Larcker (1981) recommended three conditions to assess the convergence validity of the scale project. The three conditions are that the load factor of all measurement questions is greater than 0.70 , the composite reliability (CR) of each construct exceeds 0.70 , and the average variance extract of each construct (Average Variance Extracted, AVE) should be greater than 0.50 . In addition, the reliability of the construct can be determined by examining Cronbach's alpha (required greater than 0.7 ) and CR. Table 1 shows the AVE, CR, and Cronbach 'a values for all constructs in the measurement model. It can be seen from the table that the Cronbach's alpha of each construct exceeds 0.7 , the CR value exceeds 0.8 , and the AVE value is greater than 0.5 . The reliability and convergence validity of the questionnaire are acceptable.

\section{TABLE I. CONST RUCT RELIABILITY AND CONVERGENT VALIDITY}

\begin{tabular}{|c|c|c|c|}
\hline \multirow{2}{*}{ Construct } & \multicolumn{3}{|c|}{ Reliability and validity } \\
\cline { 2 - 4 } & Cronbach's $\boldsymbol{\alpha}$ & $\boldsymbol{C . R}$. & $\boldsymbol{A V E}$ \\
\hline Achievement value & 0.771 & 0.853 & 0.592 \\
\hline Intrinsic value & 0.816 & 0.891 & 0.732 \\
\hline Utility value & 0.721 & 0.825 & 0.543 \\
\hline Social isolation & 0.869 & 0.935 & 0.878 \\
\hline Anxiety & 0.946 & 0.965 & 0.902 \\
\hline Response delay & 0.813 & 0.877 & 0.640 \\
\hline Risk of Arbitrary learning & 0.942 & 0.958 & 0.852 \\
\hline Continuance Intention & 0.821 & 0.894 & 0.737 \\
\hline
\end{tabular}

The discriminant validity is evaluated according to the recommendations of Fornell and Larcker. If the AVE square root of each construct is higher than the correlation coefficient between the construct and other constructs (Fornell \& Larcker, 1981), the construct and other constructs are explained. There is good discriminant validity between them. Table 2 lists the correlation values between constructs and the square root of AVE, which is greater than all values for the row and column it is in.

TABLE II. INTER-CONST RUCT CORRELATIONS AND DISCRIMINANT VALIDITY (I.E., BOLD NUMBERS)

\begin{tabular}{|c|c|c|c|c|c|c|c|c|}
\hline \multirow{2}{*}{ Construct } & \multicolumn{8}{|c|}{ Discriminant Validity } \\
\hline & ANX & AV & $\mathrm{Cl}$ & DR & IV & RAL & SIL & UV \\
\hline ANX & 0.950 & & & & & & & \\
\hline AV & -0.157 & 0.769 & & & & & & \\
\hline $\mathrm{Cl}$ & -0.331 & 0.638 & 0.858 & & & & & \\
\hline DR & 0.616 & -0.174 & -0.178 & 0.942 & & & & \\
\hline IV & -0.152 & 0.530 & 0.633 & -0.235 & 0.856 & & & \\
\hline RAL & 0.526 & -0.225 & -0.352 & 0.617 & 0.249 & 0.923 & & \\
\hline SIL & 0.561 & -0.041 & -0.156 & 0.467 & 0.102 & 0.587 & 0.937 & \\
\hline UV & -0.233 & 0.523 & 0.481 & -0.195 & 0.535 & -0.305 & -0.084 & 0.800 \\
\hline
\end{tabular}

\section{B. Structural Equation Model}

Figures 2 and Table 3 describe the results obtained from the PLS analysis. Five of the research hypotheses were supported, and two other research hypotheses did not reach significant levels. In terms of the variance of the interpretation, the study model explained the variance of $59.1 \%$ of the willingness to continue using MOOCs. 
TABLE III. MODEL PATH ANALYSIS

\begin{tabular}{|c|c|c|c|}
\hline \multirow{2}{*}{ The hypothesis } & \multicolumn{3}{|c|}{ Path Coefficient and significant } \\
\cline { 2 - 4 } & Path Coefficient & P-value & Support \\
\hline H1 & 0.164 & 0.034 & Yes \\
\hline H2 & 0.289 & 0.000 & Yes \\
\hline H3 & 0.341 & 0.000 & Yes \\
\hline H4 & -0.063 & 0.228 & No \\
\hline H5 & -0.228 & 0.000 & Yes \\
\hline H6 & -0.082 & 0.304 & Yes \\
\hline H7 & -0.157 & 0.048 & No \\
\hline
\end{tabular}

V. DisCUSSION

In this study, subjective task value theory is used to incorporate into the ECM model, and the influencing factors of MOOCs users' intention to use are analyzed. Seven research hypotheses are proposed. Five of these hypotheses were supported and two were not supported. Next, we will summarize and discuss the research results.

\section{A. Perceived benefits and continuance intention}

Perceived benefits in subjective task value theory include three motivational factors: achievement value, intrinsic value and utility value. Studies have shown that all three value factors have a positive impact on the continued intention of MOOCs learners to use, so H1-H3 has been confirmed. Among them, the utility value $(p=0.314, p=0.034)$ had the greatest impact on the continued intention of MOOCs users, followed by intrinsic value $(p=0.289, p=0.000)$ and achievement value $(p=0.164, p=0.000)$. In MOOCs learning, utility value refers to the external incentives that MOOCs learning can help learners get job opportunities or job promotion, salary increases. Intrinsic value refers to the user's belief that the use of MOOCs is interesting and pleasing, not targeted at specific performance, and is an intrinsic motivation of the user. Achievement motivation refers to the overall improvement of the knowledge, personal ability and confidence of the learners. From the results, MOOCs learners pay more attention to external performance such as job promotion and salary improvement. This requires MOOCs providers to pay more attention to the practicality of the MOOCs curriculum to help learners improve their abilities.

\section{B. Perceived cost and continuance intention}

The perceived cost in the subjective task value theory includes four factors: social isolation, anxiety, response delay, and risk of arbitrary learning. Studies have shown that users' anxiety $(\mathrm{p}=-0.228, \mathrm{p}=0.000)$ and risk of arbitrary learning $(\mathrm{p}=-$ $0.1578, \mathrm{p}=0.048$ ) have a significant negative impact on their continued intention to use, thus hypothesis that $\mathrm{H} 5$ and $\mathrm{H} 7$ are confirmed. . Anxiety means that MOOCs learners feel uneasy and worried about completing their learning tasks and lack confidence. In this regard, MOOCs providers should consider how to reduce learners' anxiety and improve their stickiness. Risk of arbitrary learning means that too much autonomy in the learning process will cause discomfort to the learner and be at a loss. Because the learners are not confident about their own learning ability, learning methods or learning habits, they will have the pressure and worry of learning in the process of selflearning, such as missed study time, no assignments, and no good grades. Therefore, in MOOCs, balancing autonomy and control of the learning process may be an effective way to improve the learning performance of learners with bad learning habits. In addition, social isolation and response delays have little effect on the continued intention of MOOCs learners to use, and it is assumed that $\mathrm{H} 4$ and $\mathrm{H} 6$ are not supported. This shows that in the MOOCs context, the need for communication with other learners or teachers is not obvious. The learners do not receive timely responses from teachers, teaching assistants and peers, and their influence on their continued use will not be significant.

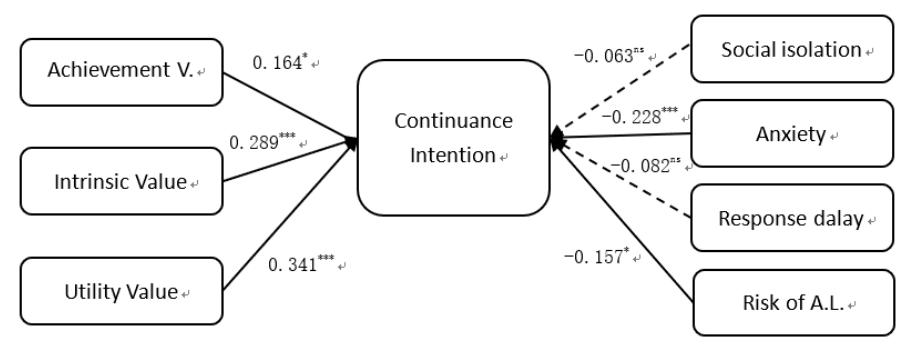

$\left({ }^{* * *}: \mathrm{p}<0.001, * *: \mathrm{p}<0.01, *: \mathrm{p}<0.05\right.$, ns - no significant $)$

Fig. 2. Structural Equation Model PLS Result

\section{ACKNOWLEDGMENT}

This work was supported in part by grants from HangZhou Dianzi University Humanities and Social Science Fund (NO.2017B08).

\section{REFERENCES}

[1] Waldrop M M. Massive Open Online Courses, aka MOOCs, Transform Higher Education and Science [EB/OL].http://www.huanqiukexue.co m/html/benqimulu/2013/0425/231 87.html, 2013.

[2] Adams A A, \&Williams S A.MOOCs: A systematic study of the published literature 2008-2012[J].The International Review of Research in Open and Distance Learning, 2013,14 ( 3):202-227.

[3] Bartolome, A., \& Steffens, K. Are MOOCs promising learning environments? Comunicar, 44, 91e99. http://dx.doi.org/10.3916/c442015-10,2015.

[4] De Barba, P. G., Kennedy, G. E., \& Ainley, M. D. The role of students' motivation and participation in predicting performance in a MOOC. Journal of Computer Assisted Learning, 2016,32, 218-231.

[5] Khaled M. Alraimi, Hangjung Zo a, Andrew P. Ciganek. Understanding the MOOCs continuance: The role of openness and reputation. (2015). Computers \& Education, 80: 28-38.

[6] Liqiang Huang, Jie Zhang, Yuan Liu. Antecedents of student MOOC revisit intention: Moderation effect ofcourse difficulty[J]. International Journal of Information Management, 2017,37 : 84-91.

[7] Chiu, C. M., \& Wang, E. T. Understanding Web-based learning continuance intention: The role of subjective task value. Information \& Management, 2008,45(3), 194-201. 